\title{
MEASUREMENTS OF RADIOACTIVITY IN AN INDUSTRIAL DIAL PAINTING ROOM
}

The radiations from radioactive substances can cause severe and lasting damage to living tissue and their effects may, in extreme cases, be lethal. These radiations are divided into three classes, viz. alpha-, beta- and gamma-rays, which are given out by radium and thorium and other radioactive elements during their disintegration. Industrial hazards arising from the use of radioactive materials occur mainly among those workers engaged in the luminous dial painting industry and the causes of injury are:

(1) ingestion of solid luminous compound by inhalation of dust or due to slovenly working habits;

(2) inhalation of radon (radium emanation); and

(3) irradiation of the whole body by gamma-rays from any accumulation of active material.

The effects of the radiations and their physical characteristics have been dealt with by Browning (1944) and G. D. Rochester (1944) and will not be described here as, in this article, it is intended to deal mainly with the practical detection of these radiations and certain aspects of the methods for protection from them.

Since this work was completed J. C. Jones and M. J. Day (1945) of Middlesex Hospital have given the results of many tests of the type to be described hereunder. It is gratifying to find that the results obtained by us agree, in order of magnitude, with those of Jones and Day. Although the work dealt with here is less exhaustive it is offered as a confirmation, by a different technique of measurement, of the results of Jones and Day.

\section{Tolerance Limits and Recommendations}

To guard against those hazards caused by the use of luminous compound and in order to establish a standard of protection, recommendations have been set down by both British (1943) and American (1941) committees, in which are stated the tolerance dosages which are regarded as compatible with the maintenance of health by a person exposed to the effects of radioactive material. There is some discrepancy between the American and British recommendations; the Americans favour tolerance dosages one-tenth of those recommended by the
British committee in dealing with radon, and approximately one-third of the British standard in the case of gamma irradiation. These tolerances are summarized in Table I. In addition, it is stressed by Curtiss (1942) and Evans (1943) that, when all three hazards are present simultaneously, the tolerances should be kept below the limits stated.

TABLE 1

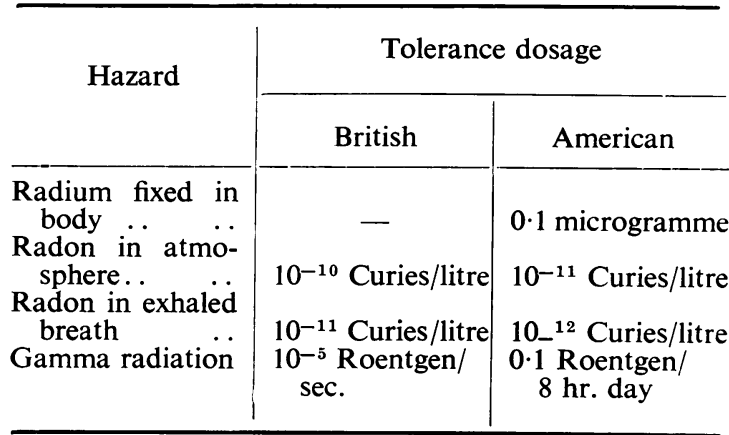

\section{Description of the Apparatus}

The measurements undertaken during this investigation fall under two main headings: gamma-ray intensity measurements, and measurements of radon in air and in the exhaled breath. Use was made of the ionization chamber method for measuring the intensity of ionization in air caused by the presence of radioactive material.

\section{Ionization Chambers}

Two forms of ionization chamber were used during the investigation, both of an approximate volume of 1 litre. The chamber used for the gamma radiation measurements is made of wire gauze and, as may be seen from Fig. 1, took the form of a cube of approximately 4-inch side. The evacuable ionization chamber is cylindrical in shape and is shown in Fig. 2. The chamber consists essentially of a brass cylinder of 4-inch inside diameter and two brass end plates. The top plate contains two tubes, one connected to the vacuum pump and the other to the sample to be admitted to the chamber. Through the bottom plate projects the central wire of the ionization chamber and it is insulated from the chamber by means of the composite insulator shown.

A difficulty which often arises in the construction of ionization chambers is the choice of material and design for the insulator through which the central electrode passes into the chamber. In the case of the wire gauze chamber an insulator of amberoid (synthetic amber) 


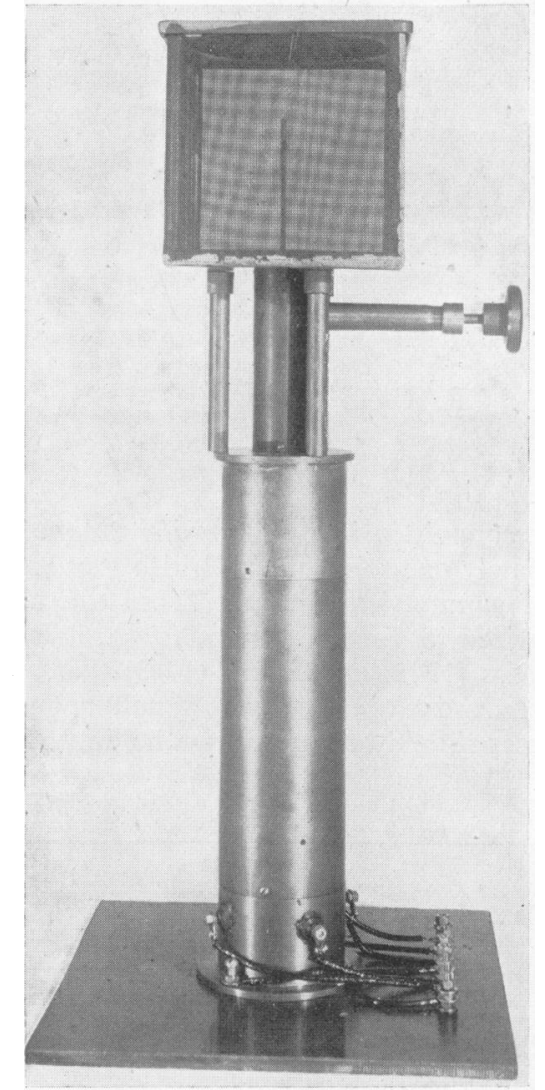

FIG, 1.-The wire-gauze ionization chamber mounted above the electrometer tube housing.

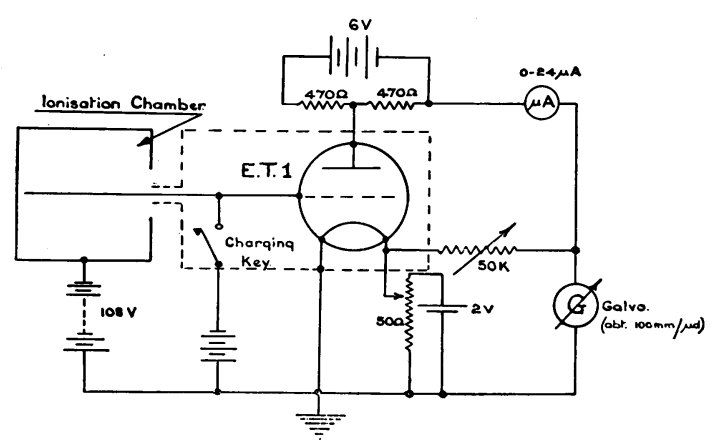

FIG. 3.-Circuit used for ionization chamber measurement.

(E.T.1=G.E.C. electrometer triode).

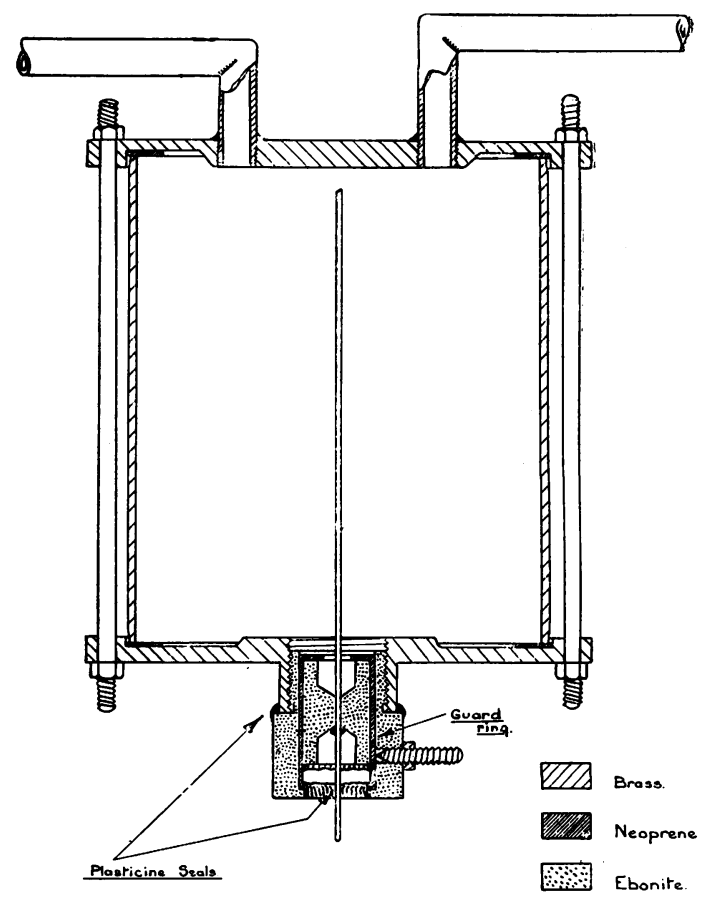

FIG. 2.-Evacuable ionization chamber.

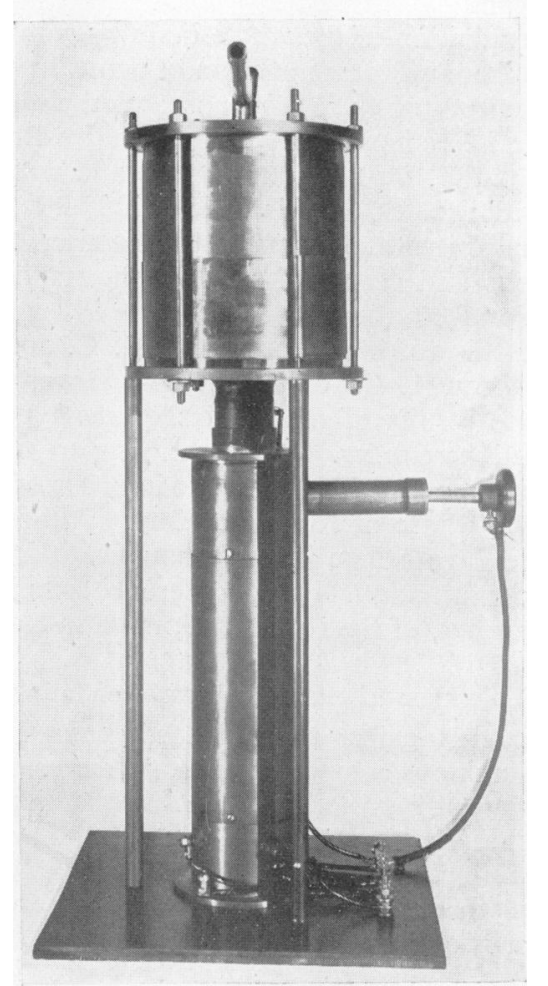

Fig. 4.-The evacuable ionization chamber and electrometer. 
was found to give adequate insulation for the range of currents measured, but the leakage across the insulator increased with time due, presumably, to contamination of its surface by atmospheric conditions. The composite insulator used in the evacuable chamber was built of ebonite coated with 'Ceresin' (a wax of non-hygroscopic character and high surface resistivity). It had been intended to build this insulator of Distrene or Trolitul synthetics which were, however, unavailable at the time. Nevertheless the wax-coated ebonite insulator showed itself entirely suitable for use in a system where the currents measured were of the order of $3 \times 10^{-14}$ ampere.

\section{Electrometer Circuit}

An ET1 Electrometer Triode was used in conjunction with the chambers described above. The circuit is shown in fig. 3 and is seen to be a d.c. amplifier of the simplest possible design. The grid is charged by means of a charging key to a fixed potential, and any subsequent leakage of charge to or from the grid, which is connected directly to the central electrode of the ionization chamber, will be detected on the galvanometer $G$ due to variation in the anode current. The rate of change of charge on the grid is a measure of the intensity of ionization and thus of the quantity of radioactive material present.

The electrometer triode itself is housed in the cylindrical brass casing to be seen in fig. 4 . This case serves as an electrical shield and also to shield the valve electrodes from light. In addition, a desiccating agent (silica gel) is placed inside the shield to prevent the glass envelope of the valve from damp and consequent lowering of the surface resistance of the valve envelope.

\section{Calibration of the Ionization Chambers}

The linearity of response of the gauze ionization chamber with variation in the distance of a radioactive source was determined by means of gamma radiation from $0.2 \mathrm{mg}$. radium. Disregarding all sources of error the rate of change of anode current should vary inversely as the square of the distance $(r)$ of the source. The experimental relation was (see fig. 5)

$$
\text { Deflection } \propto \frac{1}{r^{2 \cdot 35}} \text {. }
$$

This relation was regarded as sufficiently accurate to justify the assumption of the proportionality of the response of the chamber for a constant source at varying distance.

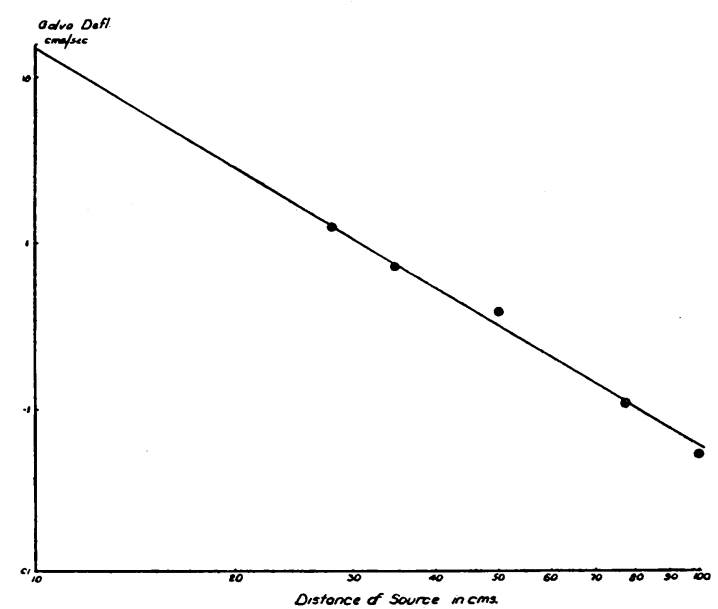

FIG. 5.-Calibration curve for 1-litre wire gauze ionization chamber with E.T.1 electrometer triode.

(Rate of Galvanometer Deflection (cm./sec.) vs. Distance of Radium Source. Galvo. Sensitivity-10 cm. per microampere. Radium Source- $0.2 \mathrm{mg}$. Ra.)
Another series of tests was carried out to determine the response to a varying source at a constant distance. A satisfactorily linear response was obtained (fig. 6) but only after precautions had been taken to prevent ionization, caused in the air around the electrometer triode itself, from counteracting the results of good insulation. The method used was to shield the electrometer from the source by means of lead blocks. Another method used by many workers is to evacuate the electrometer shield and thus reduce ionization in the residual gas to negligible proportions.

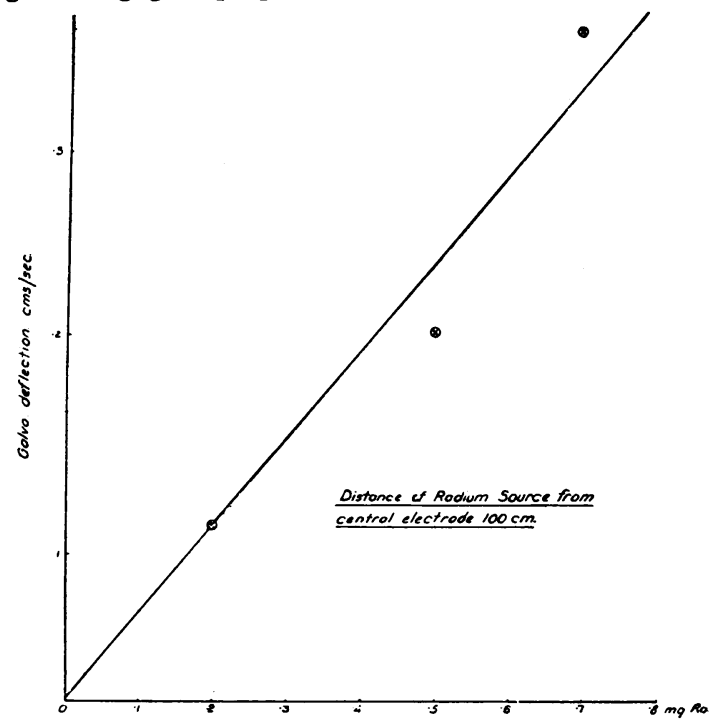

Fig. 6.-Calibration curve for 1-litre wire gauze ionization chamber with E.T.1 electrometer triode.

(Rate of Galvo. Deflection $(\mathrm{cm} . / \mathrm{sec}$.) vs. Variation in Strength of Radium Source. Galvo. Sensitivity $10 \mathrm{~cm}$. per microampere.)

In calibrating the gauze ionization chamber use was made of the equivalent relation given by the British $\mathrm{X}$-ray and Radium Protection Committee that the safe dose of $10^{-5}$ Roentgen per second is equivalent to $1 \mathrm{mg}$. Ra at a distance of $14.5 \mathrm{~cm}$. This was used as a standard and all experimental results on gamma radiation related to it.

For the calibration of the evacuable ionization chamber it was desirable to know the "radium equivalent' of the tolerance radon dose of $10^{-11}$ Curie/litre. This may be calculated by the following method. Gray (private communication) gives the number of ion pairs formed in air by an alpha particle from radon in equilibrium with its decay products as $5.52 \times 10^{5}$.

Hence the number of ion pairs emitted by 1 Curie radium per second is $3.7 \times 10^{10} \times 5.52 \times 10^{5}$ ion pairs per second where $3.7 \times 10^{10}$ is the number of $\alpha$-particles emitted per second at equilibrium by 1 Curie radium.

Now $10^{-11}$ Curie $/$ litre $=10^{-14}$ Curie $/$ c.c. and $10^{-14}$ Curie/c.c. $\equiv 3.7 \times 10^{10} \times 5.52 \times 10^{5} \times 10^{-14}$ $=204$ ion pairs/c.c./sec.

In a volume of $1 \mathrm{c.c}$. this degree of ionization will give rise to a current of $204 \times 4.8 \times 10^{-10}$ e.s.u. $/ \mathrm{sec}$. where $4.8 \times 10^{-10}$ e.s.u. is the ionic charge and, by the definition of the Roentgen $10^{-11}$ Curie/litre is equivalent to $204 \times 4.8 \times 10^{-10}$ Roentgen/sec.

It has been found * that $1 \mathrm{mg}$. radium at a distance of $14.5 \mathrm{~cm}$. gives $10^{-5}$ Roentgen $/ \mathrm{sec}$. It was found convenient to use a $0 \cdot 2 \mathrm{mg}$. capsule of radium for calibration and this was placed at a distance of

$$
14.5 \times \sqrt{0.2 \times} \sqrt{\frac{10^{-5}}{204 \times 4.8 \times 10^{-10}}}=65.5 \mathrm{~cm} .
$$
* See Report of British X-ray and Radium Protection Committee
(1943). 
Hence $10^{-11}$ Curies per litre is equivalent to $0.2 \mathrm{mg}$. Ra at $65.5 \mathrm{~cm}$.

This was the method used for calibrating the chamber and it is believed to be sufficiently accurate for the purpose of these investigations.

Another source of error to be taken into account was the question of saturation of the chamber. It is known (Klema and Barschall, 1943; Jaffe, 1929) that it is difficult to obtain complete saturation for alpha particles and measurements of current were taken over a voltage range 120-360 volts. No appreciable change in current resulted and it was therefore assumed that the ionization chamber was nearly saturated at 120 volts. This assumption was confirmed by subsequent correspondence with Mr. J. C. Jones of Middlesex Hospital, who has had very considerable experience of radon measurements.

\section{Investigations under Working Conditions}

The primary purpose of the work undertaken was to assess the safety of working conditions in the luminizing section of a large works.

Previous work undertaken to the same end had been carried out using, as a means of detection, first a simple gold-leaf electroscope and, secondly, dental films supplied and processed by the National Physical Laboratory at Teddington. The method described in this article was held to be more flexible in that it allowed beta- and gamma-ray measurements as well as radon measurements to be carried out with substantially the same apparatus, and it was also more accurate.

The room in which the measurements were made may be considered as representative of the best modern practice in the protection of workers against luminizing hazards. It was 32 feet long by 12 feet wide and was airy and well lit. There were ten booths in which dials were painted. Each one was so arranged that the worker was protected from the effect of beta and gamma radiation by the interposition of a sheet of lead glass between the work and the operative's face. Each booth was also separately exhausted in order to draw off any radon formed during work. Washing facilities were provided and also facilities for inspecting the hands under ultra-violet light in order to reveal the presence of luminescent material. Provision was made for the storage of materials and the disposal of contaminated waste, and protective clothing was provided.

Gamma radiation measurements were taken at various positions in the room, and at different times of the day and week. The results showed that at no time did the gamma-ray dosage in the room rise above 11.2 per cent. of tolerance, reaching a minimum of 5.6 per cent. under favourable conditions. Even when the measuring instrument was moved as close as possible to a booth when work was under

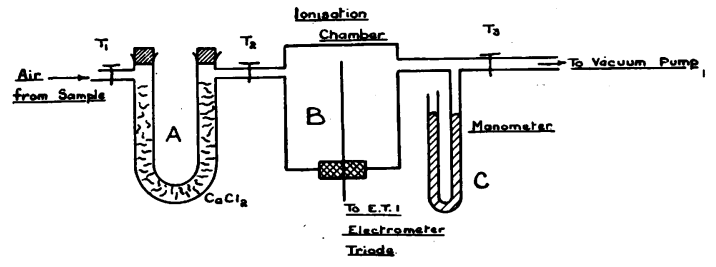

FIG. 7.-Schematic diagram of apparatus for determination of radon concentration in air. way the dosage reached no more than $27 \cdot 5$ per cent. of tolerance.

\section{Radon Measurements}

In connexion with these measurements certain precautions were necessary. Referring to fig. 7 the process of filling the chamber was as follows:-

The system was evacuated up to the tap $T_{1}$. Tap $T_{3}$ was then closed and the sample of air of which the radon content was to be measured was admitted very slowly by opening $T_{1}$. The ionization chamber, $B$, was thus filled with the air from the sample. When the pressure, as indicated on the manometer, $\mathrm{C}$, had reached that of the atmosphere, $T_{2}$ was closed and, after an interval of some minutes, measurements were taken. The necessity for admitting the sample slowly arises from the fact that, if this is not done, a spurious positive result is noted. This has been noted by other workers and attributed to the presence of moisture. The authors, however, consider that frictional charging of the incoming air might be a more likely cause.

\section{Method of Collecting Radon Samples}

In the case of measurement of the atmospheric and exhaled radon the ionization chamber was set up in the laboratory and the samples collected and transported in small latex rubber balloons. For the collection of atmospheric samples the balloons were inflated by means of a small hand pump and, in the case of the exhaled radon, the operatives were required to inflate the balloons. The exhaled samples were taken in the morning before the operatives had begun work and before they had entered the luminizing room. Ample time was thus allowed for the elimination of any radon inhaled from the atmosphere of the luminizing room (Curtiss, 1942).

\section{Results of Tests}

The measurements revealed, in all cases, that the concentration of radon both in the atmosphere and in the exhaled breath of the operatives were well below the tolerance limits, varying from 5-60 per cent. tolerance. An interesting point in these results was that there seemed to be no direct relation between the length of time an operative had worked in the luminizing room and the radon content of the exhaled breath. This would seem to point to the fact that, even under ideal conditions, a careless worker might conceivably fall victim to this industrial hazard.

\section{A Simple Ventilation Calculation}

It is useful, at this juncture, to consider the necessary rates of air flow which will, in given circumstances, keep the atmospheric radon concentrations down to the tolerance level. By making a number of simplifying assumptions the calculation becomes elementary.

Firstly we must consider the emanation of radon from luminous paint. The luminous powder contains 70 microgrammes of radium per gramme of powder. Radium evolves $2 \cdot 1$ micro-Curie radon/ sec./gramme, but owing to the slow diffusion of the gas through the varnish used to bond the powder we assume the 'emanating power' of freshly applied wet paint to be 30 per cent. and that of dry paint to be 20 per cent. (Hemeon and Evans, 1942). Hence one gramme of wet paint evolves $\frac{30}{100} \times 2.1 \times 10^{-6} \times 70 \times 10^{-6}=4.41 \times 10^{-11}$ 
Curies/g./sec. and dry paint evolves $2.94 \times 10^{-11}$ Curies/g./sec.

Taking, for example, the luminizing room dealt with in this article which measures 32 feet $\times 12$ feet $\times 12$ feet high and assuming no movement of air, we find that 90 grammes of dry paint, which is a maximum quantity stored in the room during working hours, would take

$\frac{32 \times 12 \times 12 \times 1728 \times 2.54^{3} \times 10^{-3} \times 10^{-10}}{2.94 \times 10^{-11} \times 90} \approx 82$ minutes

to bring the air in the room to a level of $10^{-10}$ Curies/ litre. Thus, allowing a factor of safety of two, the air in the room should be changed every $\mathbf{4 0}$ minutes.

Applying the same method to an individual booth of approximate volume 4 cubic feet and containing under working conditions about 5 grammes of wet luminous compound, we find that the paint emits $4.41 \times 10^{-11}$ Curies/sec./gm. which would bring the air in the booth to a level of $10^{-10}$ Curies/litre in

$$
\frac{4 \times 1728 \times 2.54^{3} \times 10^{-3} \times 10^{-10}}{5 \times 4.41 \times 10^{-11}}=51.4 \mathrm{sec} \text {. }
$$

Allowing a factor of safety of two the air in the booth should be changed in about 25 seconds, necessitating an air flow $4 \times \frac{6}{2} \frac{0}{5}=9 \cdot 6$, say 10 cubic feet per minute.

These simple calculations, although not accurate, serve to present an estimate of the ventilation needed for protection against radon concentration in the atmosphere.

\section{Summary}

The industrial hazards arising from the use of radioactive luminous compound are briefly reviewed and the tolerance limits fixed by British and American authorities summarized.

A short description of the ionization chambers and associated electrometer circuit is given and methods of calibrating the chambers are discussed.

Investigations carried out in a specific luminizing room show that the working conditions in the room are safe but it is found impossible, by means of measurement of radon in the exhaled breath, to correlate the length of time worked in the luminizing room with the radon content of the breath. This leads to the conclusion that personal habits of the operatives, even under the safest working conditions, may be the determining factor in the maintenance of health.

A simple calculation of ventilation requirements is given for certain idealized conditions.

\section{Acknowledgments}

The authors are grateful to Dr. T. E. Allibone and Mr. F. R. Perry for their interest in, and encouragement of, this work; they are also grateful to Mr. J. T. Thornhill for providing facilities for the work. Thanks are due to Sir Arthur Fleming, D.Sc., C.B.E., Director of the Research Department, Metropolitan-Vickers Electrical Company, for permission to publish this paper.

\section{REFERENCES}

Browning, E. (1944). Brit. J. industr. Med., 1, 170

Curtiss, L. F. (1942). Prevention and Control of Hazards in the Radium Dial Painting Industry. J. industr. Hyg., 24, 131 .

Evans, R. D. (1943). J. industr. Hyg., 25, 253.

Hemeon, W. C. L., and Evans, R.D. (1942). Ventilation Requirements for Radium Dial Painting. J. industr. Hyg., 24, 116.

Jaffe, G. (1929). Physik. Zeits., 30, 849.

Jones, J. C., and Day, M. J. (1945). Brit. J. Radiol., 18, 126.

Report of the British X-ray and Radium Protection Committee (1943).

Rochester, G. D. (1944). Brit. J. industr. Med., 1, 168. 